\title{
The Deformation Monitoring of Dams by the Ground-Based InSAR Technique - Case Study of Concrete Hydropower Dam Orlík
}

\author{
Milan Talich
}

\begin{abstract}
GB InSAR technique plays an increasingly important role in determining the deformation of dams. The paper describes the use of GB InSAR technique for monitoring deformations of the Czech largest concrete dam Orlík on the Vltava river. After analyzing one month-long continuous measurement of the dam were detected non-linear movements. The relation between acting water level and resulting deformations were investigated in detail. The results confirm that GB InSAR technique is very suitable for monitoring deformations of this type of constructions. At the same time, the results may serve as a valuable source of data and information for further analysis in area of stability and for early warning systems.
\end{abstract} Orlík

Keywords - GB InSAR, deformation monitoring, deformation analysis,

\section{INTRODUCTION}

This article describes the use of ground-based radar interferometry with SAR (GB InSAR or GB-SAR or TInSAR) to measure horizontal movements of dams. This method allows to simultaneously evaluate the movement of the whole dam surface. Therefore the information isn't restricted to individual reflectors, signs or sensors. The primary measurement is line of sight (LOS) movement of observed objects with relatively high spatial resolution (a few meters) and high precision (up to $0.1 \mathrm{~mm}$ ). The method is noncontact - it uses natural reflection of radar waves from the dam's surface and it is independent of external light sources allowing to observe objects regardless of day phase or weather.

\section{GB INSAR PRINCIPLES}

Several instruments for practical GB InSAR applications have been developed in the last 10 - 15 years (Rudolf et al., 1999; Harries et al., 2006). One of them is the IBIS-L (Bernardini et al., 2007). This instrument was used in presented project. The following paragraphs describe basic principles of GB InSAR as applied in the IBIS-L instrument and accompanying processing software.

Milan Talich, Institute of Information Theory and Automation of the CAS Czech Republic, Milan.Talich@utia.cas.cz, Phone: +420 603942104
IBIS-L is based on three well known technologies:

1. Stepped Frequency Continous Wave (SF-CW),

2. Radar interferometry with synthetic aperture radar (SAR),

3. Differential interferometry.

\section{A. Stepped Frequency Wave}

The continuous stepped frequency wave serves to measure the distance from radar to observed object. Microwave radiation is sent out in short high-power pulses and the distance to object is calculated from time correlation between sent and received signal. Utilizing this technology IBIS constructs a one-dimensional image called range profile. The illuminated area is divided into circular segments (resolution cells) of constant distance from radar. All targets in a given segment contribute to the observed values (amplitude and phase) of the segment. The segments' width is called range resolution $\Delta \mathrm{R}$.

The distance from radar to target is calculated from formula

$$
R_{0}=\frac{c T_{o}}{2}
$$

where $T_{0}$ is delay in response. The range resolution can be calculated from

$$
\Delta R=\frac{c \tau}{2}
$$

where $\tau$ is pulse width. This means the radar is able to discern two distinct targets only if $\Delta \mathrm{t}>\tau$ and thus $\Delta \mathrm{d}>\Delta \mathrm{R}$. Range resolution is limited by pulse width.

Figure 1 shows range resolution. $\mathrm{X}$ axis is distance from radar. The IBIS radar can distinguish targets only in one direction (in the line of sight). If there are more targets in single cell, these cannot be told apart and movement on individual targets are averaged. $\mathrm{Y}$ axis shows signal to noise ratio of received signal. 


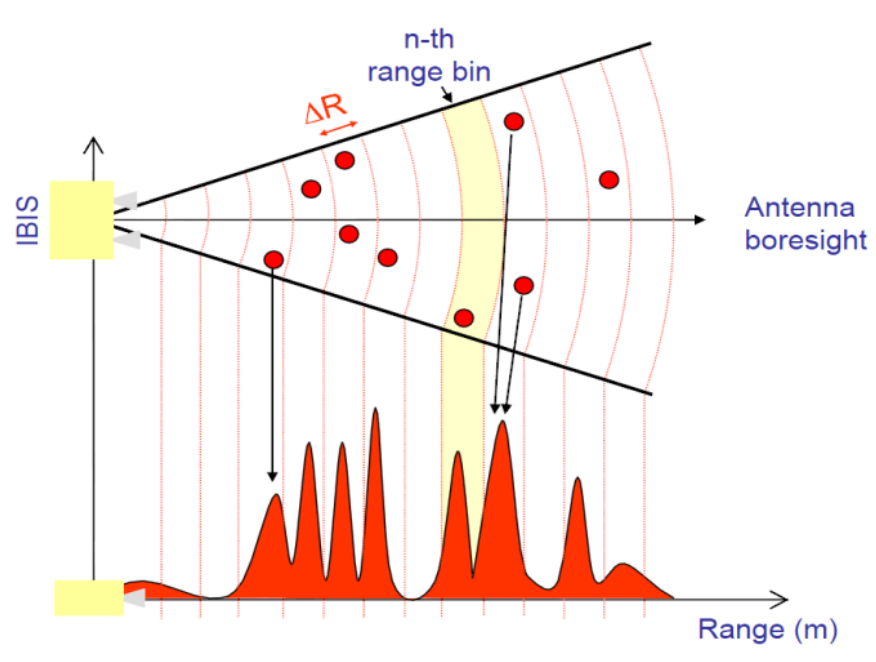

Fig. 1 Range resolution concept

\section{B. Technology SAR}

SAR (synthetic Aperture Radar) uses multiple acquisitions of given scene from separate positions to refine the crossrange resolution (Ferretti et al., 2007). The multiple acquisitions are achieved in the case of IBIS-L by moving the radar along a 2 meters rail. This allows to achieve cross-range resolution of 4.3 mrad. Combined with stepped frequency wave the IBIS-L pixel size is:

a) Range resolution: $0.75 \mathrm{~m}$,

b) Cross-range resolution: $4.3 \mathrm{mrad} \mathrm{x}$ distance.

For each of these pixels we have both amplitude (a characteristic of reflectivity) and phase (characteristic of distance) of returned signal. The phase is used in computing movements.

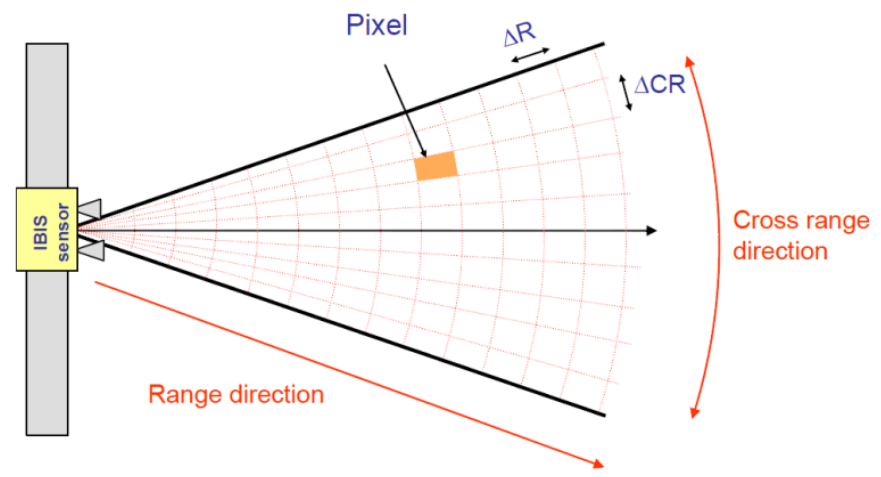

Fig. 2 Resolution grid example

\section{Radar Interferometry}

After establishing the resolution of the result image we can start to compute movements of individual pixels (and therefore parts of observed object) by the differential interferometry method. This method uses differences in phase values about pixels from two (or more) acquisitions to determine their relative movement. The principle is shown on Fig. 3.

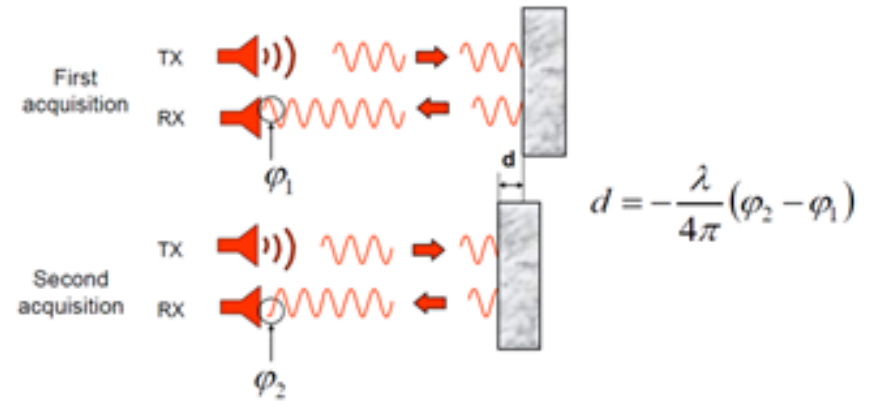

Fig. 3 Radar interferometry principle

The movements are in the line of sight of the radar (LOS) direction. There is a limit value of movement dmax between two acquisitions caused by ambiguity of observed phase. For IBIS-L this maximum movement is $4.38 \mathrm{~mm}$. If the radar's line of sight is not parallel with expected movement direction the real movements have to be computed from LOS movement using the following formula:

$$
d=d_{p} \cdot \frac{R}{h}, \text { see Fig. } 4 .
$$

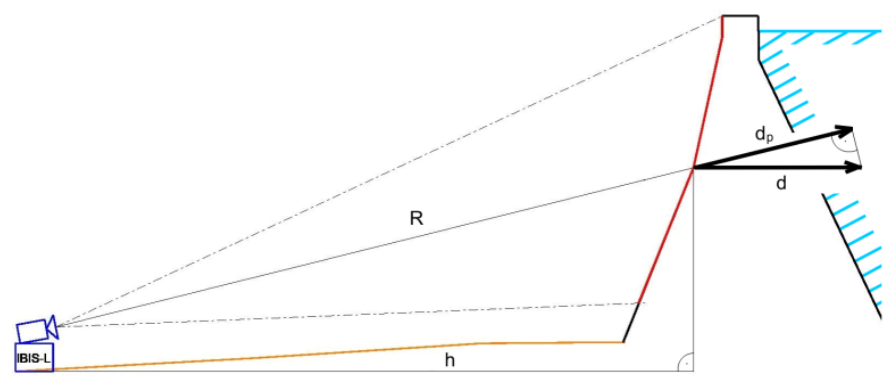

Fig. 4 Line of sight movement $\left(d_{p}\right)$ and real movement (d)

\section{Instrument Characteristics}

IBIS-L is a terrestrial coherent radar interferometer (Bernardini et al., 2007). It works in microwave spectrum with mean frequency of $17 \mathrm{GHz}$. The reflected radiation is recorded with sampling frequency from 10 to $200 \mathrm{~Hz}$. Maximum effective range is $4 \mathrm{~km}$. The standard deviation according to manufacturer is $0.1 \mathrm{~mm}$ under ideal conditions. The resolution is $0.75 \mathrm{~m}$ in range and $4.3 \mathrm{mrad} \mathrm{x}$ distance in cross-range direction.

\section{General Principles And Advantages Of GB Insar}

Ground-based interferometric radar is an instrument measuring only relative movements in its line of sight. Its nature imposes certain principles and limitations for observation:

a) Radar is not able to discern movement perpendicular to its line of sight.

b) There is a maximum movement between two subsequent acquisitions that is possible to correctly determine. This value corresponds to phase difference $\Delta \varphi=2 \pi$. For example for IBIS-L this maximum movement is $\pm 4.38 \mathrm{~mm}$ (for $\Delta \mathrm{R}=0.75 \mathrm{~m}$ ). If this value is exceeded the resulting movement is incorrect. This error cannot be detected. 
Ground-based interferometric radar has also several advantages over other monitoring systems (GNSS, extensometers):

a) It allows monitoring area of interest without the need to install additional sensors or optical targets.

b) It provides continuous map of movements for the whole illuminated area. The whole area is measured at once and the area can reach the size of hundreds of thousands of square meters. All hazardous parts of the area can be detected.

c) The movements are measured directly and in real time.

d) Observations are possible during both day and night and almost regardless of climatic conditions.

e) The radar can be wirelessly connected to remote processing and supervising station.

\section{CASE STUdy - ORLÍK WATER RESERVOIR}

As a demonstration of presented technology we conducted an observation campaign of the dam of Orlík water reservoir in the Czech Republic. The Orlík reservoir is one of the most important water reservoirs in the Czech Republic and its dam is the largest one.

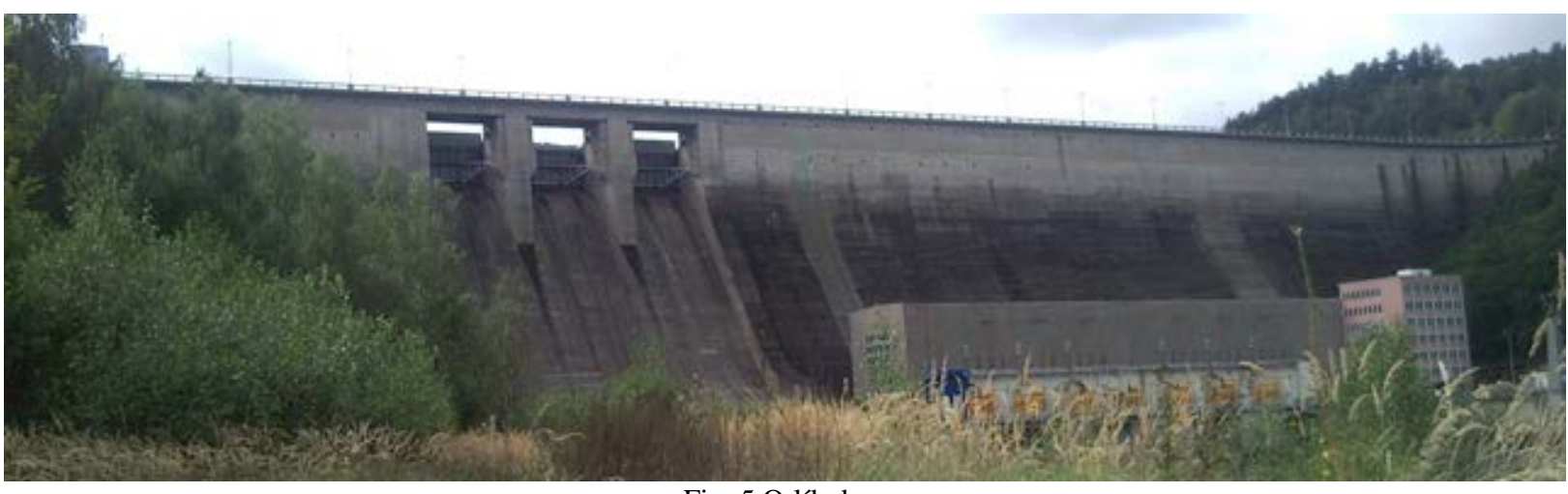

Fig. 5 Orlík dam

The dam is solid gravity dam made of concrete. It is $90.5 \mathrm{~m}$ high and $450 \mathrm{~m}$ long. Average yearly flow rate is $82.5 \mathrm{~m}^{3} \cdot \mathrm{s}^{-1}$. Water surface of the reservoir is 2732 ha, maximum depth $74 \mathrm{~m}$ and volume 716.6 million $\mathrm{m}^{3}$. Emergency spillway is composed of three fields, each of them $15 \mathrm{~m}$ wide and with $8 \mathrm{~m}$ high locks.

The campaign lasted from 20th August to 2013 to 13th September 2013 i.e. 24 days. The data acquisition frequency was 30 minutes for the first 13 days and 5 minutes for the last 11 days. The radar was placed on temporary concrete fittings because no other observations were planned. Mean distance from radar to dam was $350 \mathrm{~m}$. Antennas type 6 (IBIS-ANT6H51V20) were used. Atmospheric data were obtained from nearest public meteorological station. Data about water height were provided by the dams operator - Povodí Vltavy. These data show small regular daily fluctuations of water height caused by water releases. The only more significant change occurred between 5th and 9th September, when the surface dropped by approximately $75 \mathrm{~cm}$ (see Fig. 9).

\section{A. Processing and Results}

The basic result of processing GB InSAR observations is a 2D image showing the movements of the area of interest in the whole time window. This image can be placed as a texture on 3D model of the dam for better visualization - see Fig. 6.

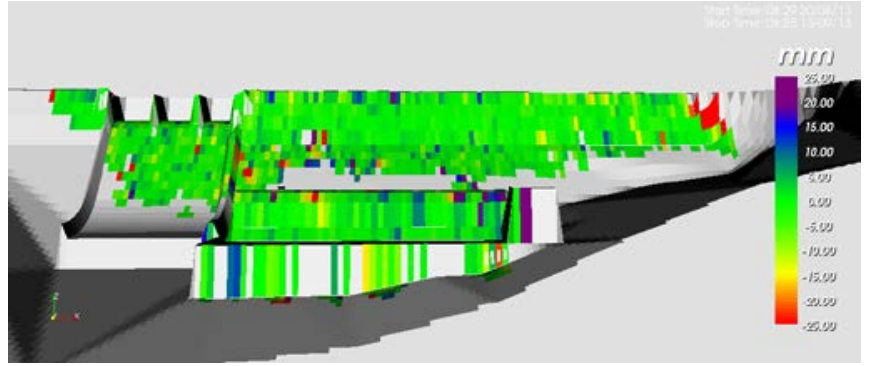

Fig. 6 Total movements for 24 days

The detected movements visualization shows positive movements (away from radar) with blue color and negative movements (towards the radar) with red color. Here we can discern isolated points showing significant unexpected movements unrelated to their surroundings. These points lie in various parts of the dam. The points along the dam's top are affected by reflections from lamps and railing. The points on the dam's slope are locations where support wires are anchored to the dam. The points on power plant's building are affected by reflections from transformers and their wiring. These points have to be considered as invalid and left out from further analysis. 


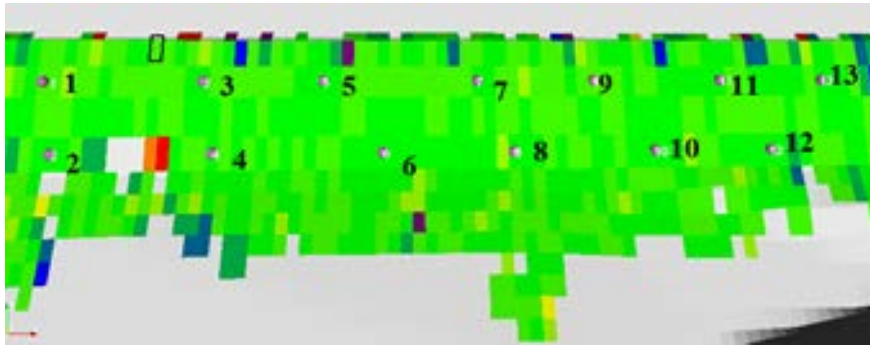

Fig. 7 Position of points selected for analysis

To illustrate the movement analysis of individual points we will select points under the dam's top. Their location is shown on Fig. 7. Fig. 8 shows the movement of points 1, 3, 5, 7,11 and 13 during the whole campaign. Their movement is in the range of $\pm 2 \mathrm{~mm}$.

Some points show periodical tendencies in their movement. Especially between 6th September and 9th September points 7,11 , and 3 show daily periods. For example point 7 moves during that time daily from $+0.2 \mathrm{~mm}$ to $-0.7 \mathrm{~mm}$. The likely cause is sunshine lighting and warming the dam. Situation is on the Fig. 9. Cause of the biggest movements of point 1 in Fig. 8 is not known.

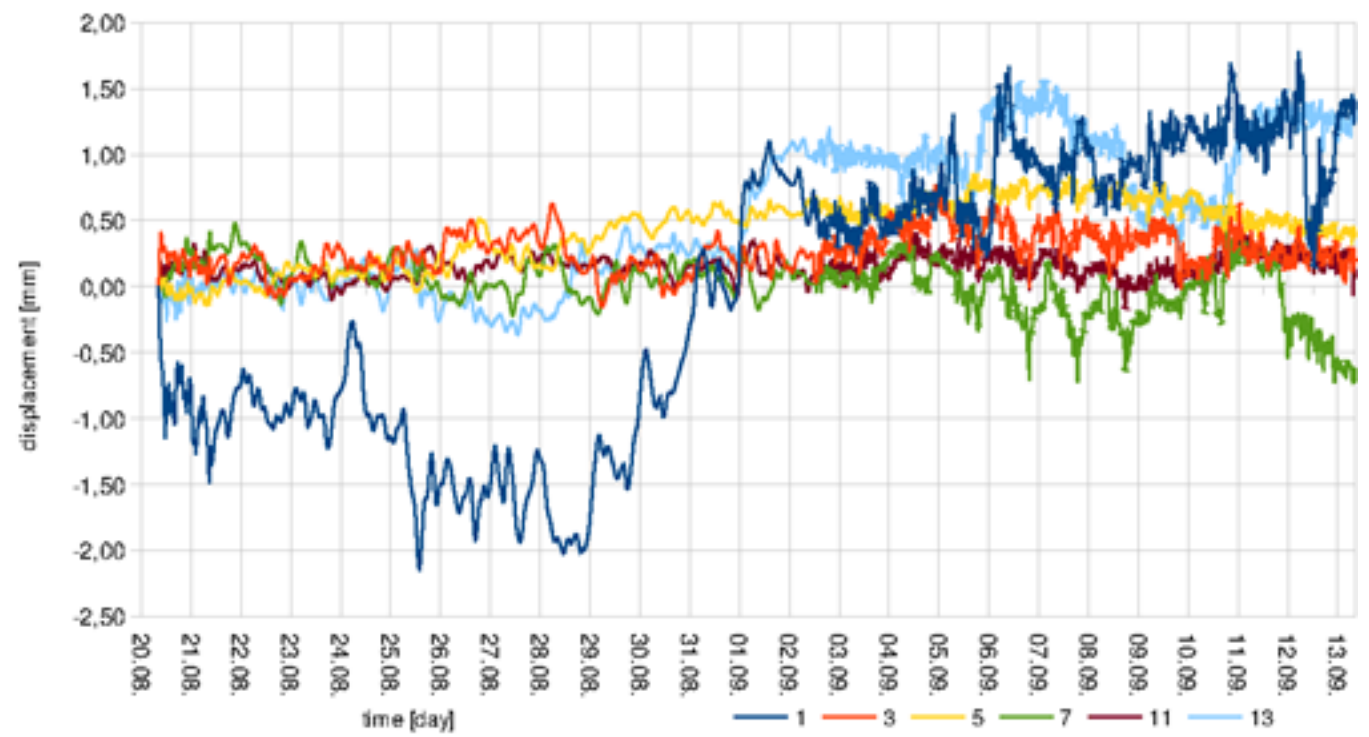

Fig. 8 Movement of selected points for 24 days

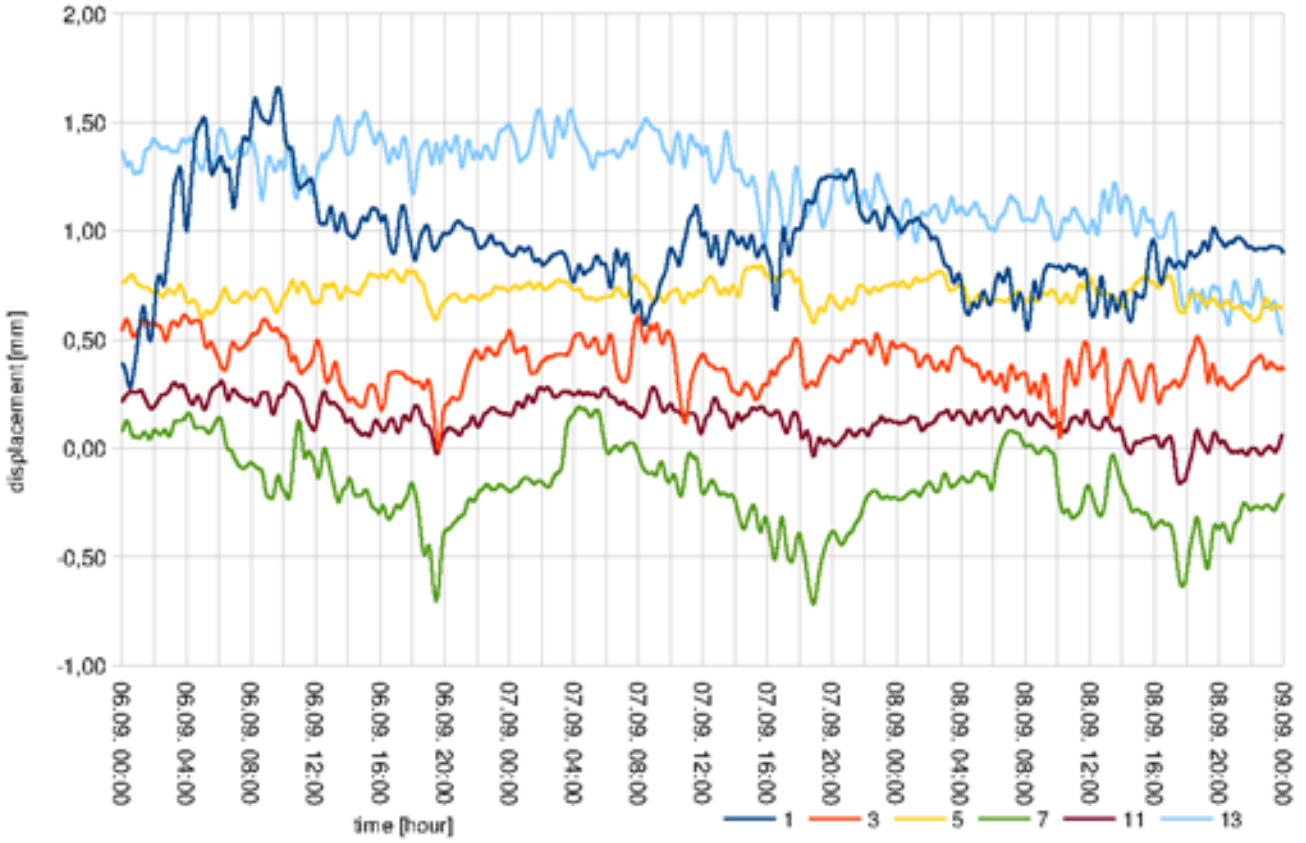

Fig. 9 Movement of selected points for selected 3 days 


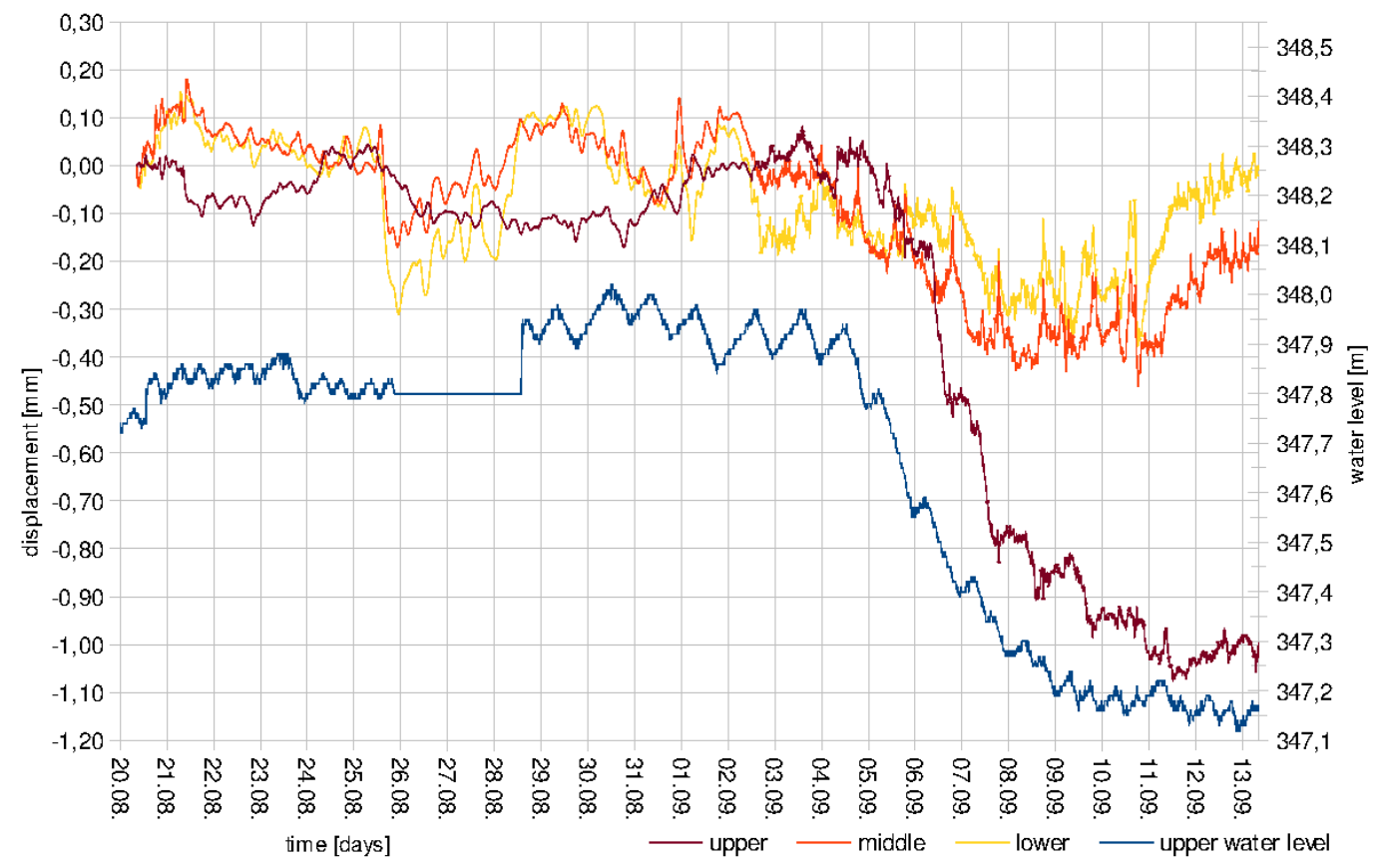

Fig. 10 Average movements of upper, middle and lower parts of dam

For analysis the dam's movement as a whole the dam was divided into three approximately equal horizontal parts: upper part (under dam's top), middle and lower part. Fig. 10 shows average movements of these parts for the whole campaign. Middle and lower parts show very high level of similarity considering the precision of measurement. The upper part has a different trend and shows the biggest differences between 5th and 9th September (where considerable water release took place). Interesting information is that a fast drop in water height about $0.7 \mathrm{~m}$ during four days caused movement of the upper part of the dam downstream about $0.9 \mathrm{~mm}$.
A separate part of the processing is an analysis of movements of metal locks of the emergency spillways. The assumption was the water pressure and it's changes would clearly show in movements of these locks. We selected two points on each lock placed symmetrically in regards to its vertical axis. Fig. 11 shows movements of points 5 and 6 for all 24 days and Fig. 12 shows it in detail for 4 selected days. We can see significant periodical movement of both points. One of the points moves downstream, the second upstream. The daily period is likely caused by changes in temperature and lighting of the locks.

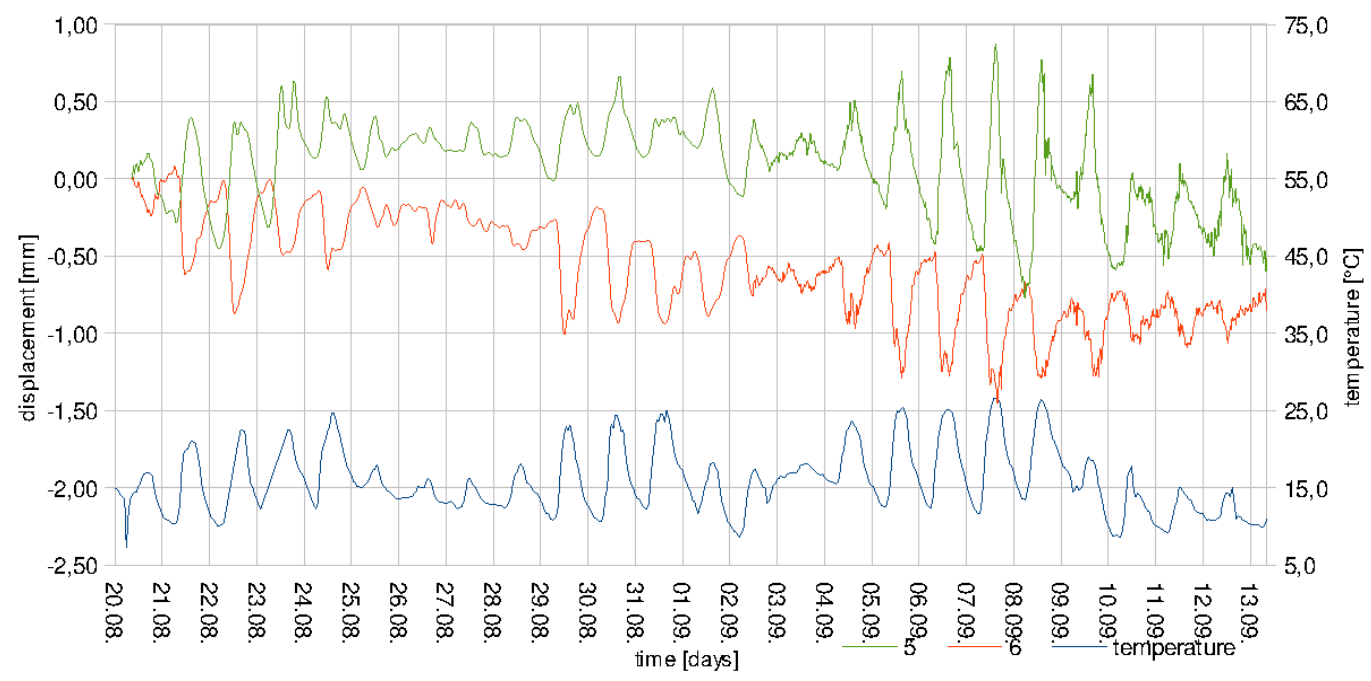

Fig. 11 Movements of selected points on emergency spillways' gates for 24 days 


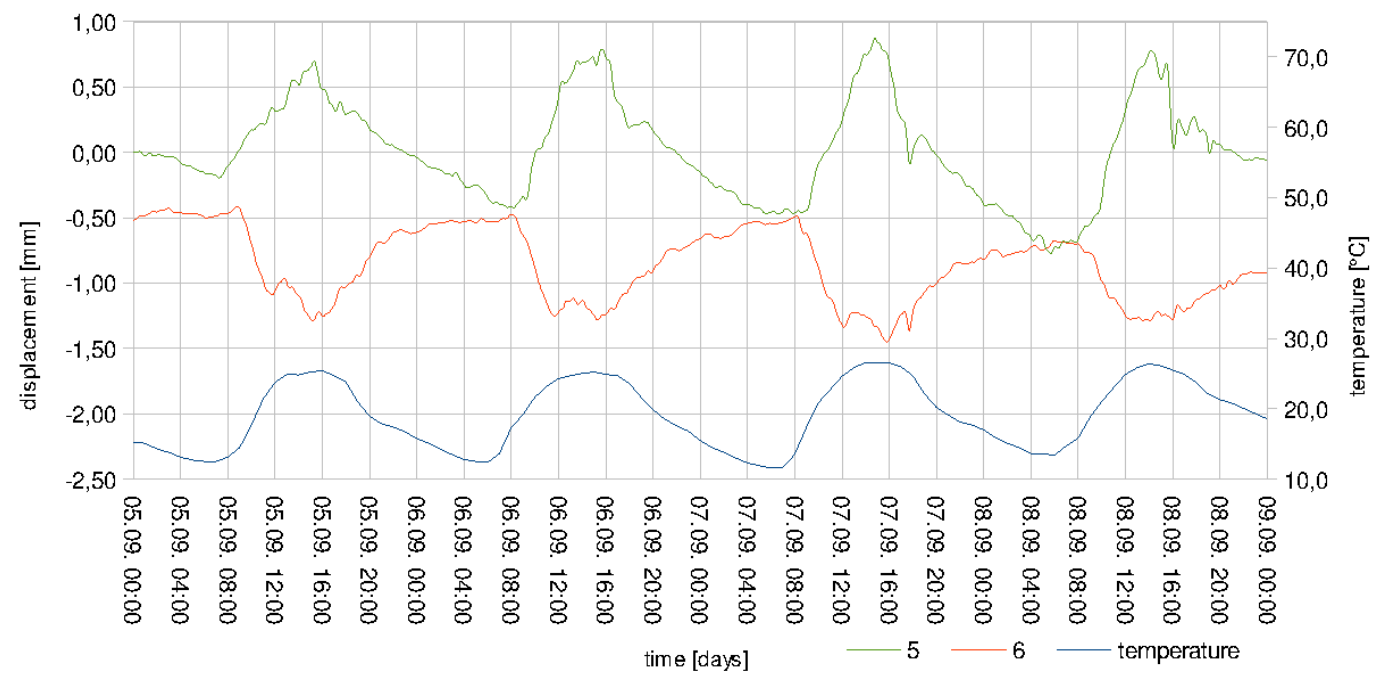

Fig. 12 Movements of selected points on emergency spillways' gates for 4 selected days

\section{CONCLUSION}

The presented observation campaign proved the feasibility of GB InSAR for observation of dams. Success of the observation and quality of results are dependent on quality of dam's reflection. The observations can be negatively affected in various parts of dam by multiple reflections or by movement of loose parts (wiring, railing, lamps, etc.).

At the same time it proves that horizontal movements of the Orlík dam are of such magnitude and speed as to warrant long term observation. These are principally periodical movements dependant of external effects - changes in temperature, lighting, water height etc. For example some points in the upper parts of the dam show movements of ca $0.9 \mathrm{~mm}$. Analysis of the movements of the emergency spillways locks shows again periodical daily movements up to $1.5 \mathrm{~mm}$. The results confirmed assumptions about the influence of water height. Fast drop of the water surface caused movements of the dam's upper part of ca $0.9 \mathrm{~mm}$.

\section{ACKNOWLEDGMENT}

This contribution was supported by the Ministry of Industry and Trade of the Czech Republic, project "Investigation of terrestrial InSAR efficiency for deformation analysis of hazardous objects and localities”, (P-InSAR), FR-TI4/436.

Every measurement was carried out within the project PInSAR by employees of the Geodézie Ledeč nad Sázavou s.r.o surveying company.

\section{REFERENCES}

[1] Alba, M., Bernardini, G., Giussani, A., Ricci, P., Roncoroni, F., Scaioni, M., Valgoi, P. and Zhang, K., 2008. Measurement of dam deformations by terrestrial interferometric techniques. In: ISPRS Congress, Beijing, China, Jul 3-11, 2008, The International Archives of the Photogrammetry, Remote Sensing and Spatial Information Sciences, Vol. XXXVII, Part B1, 2008.

[2] Bernardini, G., De Pasquale, G., Bicci, A., Marra, M., Coppi, F., Ricci, P. and M. Pieraccini, 2007. Microwave interferometer for ambient vibration measurements on civil engineering structures: 1 .
Principles of the radar technique and laboratory tests. In: Proc. of EVACES'07, Porto, Portugal, 24-26 Oct, on CDROM.

[3] Ferretti, A., Monti Guarnieri, A., Prati, C., Roca, F., Massonet, D., 2007. InSAR Principles: Guidelines for SAR Interferometry Processing and Interpretation. ESA Publications, Noordwijk, The Nederlands.

[4] Harries, N., Noon, D., and K. Rowley, 2006. Case Study of Slope Stability Radar used in Open Cut Mines. In: Proc. of Int. Symp. on Stability of Rock Slopes in Open Pit Mining and Civil Eng., Cape Town, South Africa, 3-6 Apr, pp. 335-342.

[5] Pieraccini, M., Luzi, G., Mecatti, D., Noferini, L., Macaluso, G., Atzeni, C., 2006. Ground-Based radar interferometry for monitoring unstable slopes. In: 3rd IAG/12 FIG Symposium, Baden, May 22-24, 2006.

[6] Rudolf, H., Leva, D., Tarchi, D., and J. Sieber, 1999. A mobile and versatile SAR system. In Proc. of IGARSS '99, Vol. 1, 28 June-2 July, Hamburg, Germany, pp. 592-594.

http://dx.doi.org/10.1109/igarss.1999.773575

[7] Sărăcin, A., Coșarcă, C., Jocea, A., 2012. Dam deformation measurements using terrestrial interferometric techniques, University “1 Decembrie 1918” of Alba Iulia, GeoCAD 2012.

[8] Talich M., Glöckner M., Böhm O., Antoš F., Soukup L., Havrlant J., Šolc J.: The Application of the Ground-based InSAR technique for the deformation monitoring of concrete hydropower dam Orlík on Vltava river. In: INGEO 2014 - 6th International Conference on Engineering Surveying, Prague, Czech republic, April 3-4, 2014, pp. 203-210, ISBN 978-80-01-05469-7

\section{About Author:}

Milan Talich, Ph.D., was graduated from the Czech Technical University in Prague, Faculty of Civil Engineering, Department of Geodesy and Cartography. Then he was engaged in the Research Institute of Geodesy, Topography and Cartography (VÚGTK), working since 1987 in the International Centre on Recent Crustal Movement (ICRCM) at geodetic networks processing and geodynamic problems, later in geoinformation technology. Since 2012 he work also in the Institute of Information Theory and Automation of the CAS (Czech Academy of Sciences) at using GB SAR technology for determining of deformation. 